\title{
Functional analysis of plant genes related to Arbuscular Mycorrhiza symbiosis using Agrobacterium rhizogenes- mediated root transformation and hairy root production
}

Tania Ho-Plágaro, María Isabel Tamayo-Navarrete, and José Manuel García-Garrido.

Department of Soil Microbiology and Symbiotic Systems, Estación Experimental del Zaidín (EEZ), CSIC, Calle Profesor Albareda n॰1, 18008 Granada, Spain

\section{Abstract}

Arbuscular Mycorrhizal symbiosis is a mutualistic endosymbiosis widely distributed in the plant kingdom which has a significant impact on plant growth and health. Agrobacterium rhizogenes-mediated root transformation and composite plant generation have been described as a rapid method to assess gene functions in roots without the need for stable transformation plant production. We describe an optimized protocol for composite tomato plant obtaining achieved through A. rhizogenes-mediated transformation, and we also highlight key differences with other protocols that should be taken into account to adjust this method to the transformation of other plant species. This protocol has been adopted as a useful tool for localizing the promoter expression of genes putatively associated with mycorrhization or for functional analyses in mycorrhizal studies by reverse genetics.

Key words $A$. rhizogenes, Transformation, Composite plants, Hairy roots, Tomato 


\section{Introduction}

Plant transformation using Agrobacterium rhizogenes is a reliable technique which represents a much faster alternative than stable transformation with A. tumefaciens. In contrast to A. tumefaciens, A. rhizogenes contains the root locus (rol) genes, whose induction triggers the development of adventitious genetically transformed roots, the socalled "hairy roots", a name firstly attributed by Stewart et al. (1). This natural phenomenon has been deeply studied (2) and widely applied as a biotechnology tool for functional analyses of genes in research focused in plant roots, including biotic interactions with microbes $(3,4)$, root-knot nematodes $(5,6)$ and parasitic plants (7). In addition, we must also highlight the great potential of A. rhizogenes hairy root cultures for mass production of secondary metabolites $(8,9)$.

Transformation using A. rhizogenes enables the generation of healthy plants consisting of untransformed shoots together with transgenic hairy roots, known as "composite plants". The transgenic hairy roots can also be isolated in in-vitro cultures and used for clonal propagation of hairy root explants without the requirement of additional plant hormones (10). Furthermore, stably transformed plants have been regenerated from transgenic hairy roots $(2,11)$.

Plant transformation through Agrobacterium is based on inoculation of a plant with Agrobacterium strains carrying a binary vector with a T-DNA containing either the transgene, the hairpin RNAi fragment or the promoter of interest (12). In the case of the use of an A. rhizogenes strain, some of the hairy roots will be cotransformed with both the binary vector with the corresponding T-DNA, and also the helper plasmid with the rol and vir genes which induce the production of hairy roots and allow integration of the T-DNA into the host genome $(13,14)$. For this reason, these transgenic roots are also usually named as "cotransformed hairy roots".

Many genes have been demonstrated to play important roles during mycorrhizal symbiosis or nodulation using the hairy root transformation method (15-18). A transgene of interest can be downregulated by RNA interference or overexpressed in order to determine its underlying function. Moreover, cells where a specific promoter is expressed can be localized by a promoter-reporter construct, and localization of a particular protein can also be analysed by a construct of the transgene fused to a fluorescent tag.

The protocol described in this chapter is based on the Ho-Plágaro et al. (19) procedure, which is adjusted for the obtaining of Solanum lycopersicum composite plants with transgenic hairy roots that overexpress or silence specific genes putatively involved in the mycorrhization process, and to localize the expression of the corresponding promoters. Here, we include detailed information regarding how to generate the Gateway-based constructs employed, all of them containing the DsRed fluorescent marker gene in order to easily select the cotransformed roots and tracking the success of the transformation procedure. We provide tips and recommendations for a successful 
application of the protocol published earlier (19). A compilation of protocols used for composite plant generation in different plant species for the study of mycorrhizal symbiosis is also enclosed in this chapter.

\section{Materials}

\subsection{Preparation of Agrobacterium strains for plant transformation}

1. PCR reagents: sterile deionized $\mathrm{H}_{2} \mathrm{O}$, oligonucleotide primers, DNA template, deoxynucleotide triphosphate (dNTPs), Taq polymerase buffer, Taq polymerase.

2. Gateway reagents: LR Clonase II enzyme mix, Proteinase K (Invitrogen, Carlsbad, California).

3. Plasmids: donor vector with attP sites (pENTR/D-TOPO) (Invitrogen $\mathrm{nc}$.); binary destination vectors with attR sites appropriate for RNAi (pK7GWIWG2(II)-RedRoot (https://gateway.psb.ugent.be/), overexpression (pUBIcGFP-DR, (20)) and promoter-GUS expression analysis (pBGWFS7::pAtUbq10::DsRed, modified from Karimi et al. (21).

4. Primers: M13 forward primer and (5' TGT AAA ACG ACG GCC AG 3'), M13 reverse primer (5' CAG GAA ACA GCT ATG ACC 3'), and primers for amplification of the corresponding RNAi, CDs or promoter fragments.

5. LB Medium: $10 \mathrm{~g}$ tryptone, $5 \mathrm{~g}$ yeast extract, and $5 \mathrm{~g} \mathrm{NaCl}$ dissolved in $900 \mathrm{~mL}$ MilliQ $\mathrm{H}_{2} \mathrm{O}$. Adjust the final volume to $1 \mathrm{~L}$. For plate preparation, $15 \mathrm{~g}$ of agar is added per litre of LB.

6. Antibiotics: spectinomycin (100 $\mathrm{mg} / \mathrm{mL}$ stock solution), streptomycin (100 mg/mL stock solution), and kanamycin (50 mg/mL stock solution).

7. Round $9 \times 9 \mathrm{~cm}$ Petri plates.

8. DB3.1 and One Shot TOP10 E. coli heat-shock competent cells (Invitrogen).

9. A. rhizogenes MSU440 strain cells.

10. Electroporation cuvettes and electroporator.

\subsection{In vitro generation of composite plants}

1. Solanum lycopersicum cv Moneymaker seeds.

2. Bleach solution containing $2.35 \% \mathrm{w} / \mathrm{v}$ sodium hypochlorite $(50 \% \mathrm{v} / \mathrm{v}$ commercial bleach). 
3. $12 \times 12 \mathrm{~cm}$ squared Petri plates.

4. $0.5 x$ MS $0.8 \%$ agar medium: Add $4.4 \mathrm{~g}$ of Murashige and Skoog media (22) (Duchefa Biochemie) and $160 \mathrm{~g}$ Plant-Agar (Duchefa Biochemie) in $1800 \mathrm{~mL} m Q \mathrm{H}_{2} \mathrm{O}_{2}$. Adjust the $\mathrm{pH}$ : 5.7-5.8. Adjust the final volume up to $2 \mathrm{~L}$ and autoclave.

5. $0.5 x$ MS $0.8 \%$ agar medium without vitamins: Add 4.4g of Murashige and Skoog media without vitamins (22) (Duchefa Biochemie) and $160 \mathrm{~g}$ Plant-Agar in $1800 \mathrm{~mL} m Q \mathrm{H}_{2} \mathrm{O}_{2}$. Adjust the $\mathrm{pH}$ : 5.7-5.8. Adjust the final volume up to $2 \mathrm{~L}$ and autoclave.

\subsection{AM inoculation and plant growth in pots}

1. Expanded clay, vermiculite and coconut fibre.

2. 500-mL pots.

3. Plastic glasses or humidity domes.

4. Water sprayer.

5. Modified Long Ashton nutrient solution (23) (Table 1) containing $25 \%$ of the standard phosphorous concentration. The amount of $\mathrm{Na}_{2} \mathrm{HPO}_{4}$ of the nutrient solution was reduced to $1 / 4$ (final concentration $324.51 \mu \mathrm{M}$ ) in order to prevent mycorrhizal inhibition due to an excess of $\mathrm{P}$. The $\mathrm{pH}$ of the media was adjusted to 7 with $\mathrm{NaOH}$.

6. Rhizophagus irregularis inoculum (DAOM 197198).

Table 1 Modified Long Ashton nutrient solution with 1/4 Pi

\begin{tabular}{lrr}
\hline & \multicolumn{2}{c}{ Complete nutrient solution } \\
& $\mathrm{mg} \mathrm{l}^{-1}$ & $\mu \mathrm{M}$ \\
\hline Macroelements & & \\
$\mathrm{KNO}_{3}$ & 303 & 2990.03 \\
$\mathrm{Ca}\left(\mathrm{NO}_{3}\right)_{2}$ & 1416 & 8629.52 \\
$\mathrm{MgSO}_{4} \cdot 7 \mathrm{H}_{2} \mathrm{O}$ & 368 & 1493.68 \\
\hline $\mathrm{Na}_{2} \mathrm{HPO}_{4} \cdot 2 \mathrm{H}_{2} \mathrm{O}$ & 58 & 324.51 \\
\hline $\mathrm{EDTA}-\mathrm{Fe}(\mathrm{II})$ & 25 & 72.24 \\
Microelements & & \\
$\mathrm{MnSO}_{4} \cdot 4 \mathrm{H} 2 \mathrm{O}$ & 2.20 & 9.86 \\
\hline $\mathrm{H}_{3} \mathrm{BO}_{3}$ & 1.86 & 30.08 \\
$\mathrm{CuSO}_{4} \cdot 5 \mathrm{H}_{2} \mathrm{O}$ & 0.24 & 0.96 \\
\hline $\mathrm{ZnSO}_{4} \cdot 2 \mathrm{H}_{2} \mathrm{O}$ & 0.29 & 1.47 \\
$\mathrm{Na}_{2} \mathrm{MoO}_{4} \cdot 2 \mathrm{H}_{2} \mathrm{O}$ & 0.03 & 0.12 \\
\hline
\end{tabular}




\subsection{Confirmation of transformed nature of hairy roots}

\subsubsection{Selection of DsRed Hairy roots}

1. A fluorescence stereo-microscope equipped with a red filter 2.4.2 Quantification of the level of gene silencing or overexpression

1. RNeasy Plant Mini Kit (Qiagen, Hilden, Germany).

2. RNase-Free DNase.

3. iScriptTM cDNA synthesis kit (Bio-Rad, Hercules, CA, USA).

4. SYBR Green Supermix (Bio-Rad, Hercules, CA, USA).

5. RT-qPCR primers $(10 \mu \mathrm{M}$ stocks $)$.

\subsection{Localization of promoter expression for the genes of interest}

1. GUS staining solution: $0.05 \mathrm{M}$ sodium phosphate buffer, $1 \mathrm{mM}$ potassium ferrocyanide, $1 \mathrm{mM}$ potassium ferricyanide, $0.05 \%$ Triton X-100, $10.6 \mathrm{mM}$ EDTA-Na and $5 \mu \mathrm{g} / \mathrm{mL} \quad \mathrm{X}$-gluc cyclohexylammonium salt (previously dissolved in $\mathrm{N}, \mathrm{N}$ dimethylformamide).

2. PBS $1 \mathrm{X}$ solution: dissolve $8 \mathrm{~g}$ of $\mathrm{NaCl}, 0.2 \mathrm{~g}$ of $\mathrm{KCl}, 1.44 \mathrm{~g}$ of $\mathrm{Na}_{2} \mathrm{HPO}_{2}$ and $0.24 \mathrm{~g}$ of $\mathrm{KH}_{2} \mathrm{PO}_{4}$ in $800 \mathrm{~mL}$ of distilled $\mathrm{H}_{2} \mathrm{O}$. Adjust the $\mathrm{pH}$ to 7.4 and adjust the final volume up to $1 \mathrm{~L}$. Autoclave.

3. $4 \%$ agarose in PBS $1 X$.

4. WGA-Alexa Fluor 488 conjugate (Molecular Probes, Eugene, Oreg., USA) in PBS $1 \mathrm{X}(200 \mu \mathrm{g} / \mathrm{ml}$ stock aliquots $)$.

5. Vibratome (Leica VT1200S).

6. Vacuum chamber.

7. Inverted fluorescent microscope (Leica DMI600B).

\subsection{Characterization of symbiotic phenotype resulting from alterations of plant host genes}

2.6.1 Trypan blue staining of AM fungal structures-Morphologic analysis of intraradical hypha and arbuscule development

1. $10 \% \mathrm{KOH}$ : Dissolve $100 \mathrm{~g}$ of $\mathrm{KOH}$ in $900 \mathrm{~mL}$ of Milli-Q water and adjust the final volume to $1 \mathrm{~L}$. 
2. $0.1 \mathrm{~N} \mathrm{HCl}$ solution: Add $9.85 \mathrm{~mL}$ of concentrated $\mathrm{HCl}$ (around $37 \% \mathrm{HCl}$ ) in $990 \mathrm{~mL}$ of water.

3. Lactic acid.

4. $0.05 \%$ Trypan blue: Dissolve $0.5 \mathrm{~g}$ of Trypan blue in $1 \mathrm{~L}$ of lactic acid, and store in a glass bottle.

2.6.2 Morphologic analysis of intraradical hypha and arbuscule development

1. PBS $1 X$ solution (see Subheadling 2.5)

2. WGA-Alexa Fluor 488 conjugate (Molecular Probes, Eugene, Oreg., USA) in PBS $1 \mathrm{X}(200 \mu \mathrm{g} / \mathrm{ml}$ stock aliquots $)$.

3. Vacuum chamber.

4. Inverted fluorescent microscope (Leica DMI600B).

\subsubsection{Analysis of gene expression of AM-marker genes}

Same materials as in Subheading 2.4.2.

\section{Methods}

\subsection{Preparation of Agrobacterium strains for plant transformation}

The most common and easy method for generating expression constructs is by using the Gateway cloning technology. This procedure involves three steps: step 1, generation of the entry vector; step 2, recombination into the destination vector; and step $\mathbf{3}$, Agrobacterium rhizogenes transformation with the resulting constructs.

\subsubsection{Cloning of Genes of Interest into the pENTR/D-TOPO entry vector}

Entry clones suitable for subsequent LR clonase reactions must have attL1 and attL2 sites. These entry clones can be generated in different ways, from which we will show the most convenient one, which is the TOPO cloning.

1. Design a set of oligonucleotide primers complementary to the target region, with the forward primer containing a $5^{\prime} \mathrm{CACC}$ additional sequence, in order to generate a PCR product with a CACC overhang at the 5'end that complements the GTGG overhang in the cloning vector, ensuring efficient directional cloning (see Note 1). Amplify the target region through PCR from cDNA (for CDs or RNAi fragment) or genomic DNA (promotor sequence) using a blunt-endgenerating DNA polymerase (see Note 2). 
2. Visualize in an agarose electrophoresis gel an aliquot of the PCR product to check if it has been successfully amplified. If the product is unique we can directly purify the PCR reaction product. If the PCR amplification generates additional unspecific PCR products, visualize and excise the corresponding gel band exposing the gel to a UV transilluminator and using a scalpel blade (see Note 3). When cutting the band, include as little of the surrounding gel as possible to improve subsequent purification. Finally, purify the corresponding gel band. For purification of the PCR product, either from a PCR reaction or from a gel band, use, for example, the DNA and Gel Band Purification Kit (GE Healthecare).

3. Electrophorese an aliquot of the purified PCR product alongside quantitative DNA markers to determine DNA concentration.

4. Clone the PCR purified product into the $\mathrm{pENTR/D-TOPO}$ vector by using the pENTR Directional TOPO Cloning Kit (Invitrogen). To obtain the highest cloning efficiency, it is recommended to use a PCR product: TOPO vector molar ratio of $0.5: 1$ to $2: 1$. For example, you may calculate a $1: 1$ molar ratio following the formula below:

$$
\frac{20 \mathrm{ng} \mathrm{pENTR} / \mathrm{D}-\mathrm{TOPO} \text { vector } \mathrm{x} \mathrm{Kb} \text { PCR product }}{2.5 \mathrm{~Kb} \mathrm{pENTR} / \mathrm{D}-\mathrm{TOPO} \text { vector }} \times \frac{1}{1}=\text { ng of PCR product }
$$

The cloning reaction is set up in a $0.5 \mathrm{~mL}$ low-retention microtube at room temperature by mixing $0.5-4 \mu \mathrm{L}(2-4 \mathrm{ng})$ of fresh, gel-purified PCR product, 1 $\mu \mathrm{L}$ salt solution $(1.2 \mathrm{M} \mathrm{NaCl}$ and $0.06 \mathrm{M} \mathrm{MgCl} 2), 1 \mu \mathrm{L}(20 \mathrm{ng}) \mathrm{pENTR} / \mathrm{D}-$ TOPO vector and sterile water to make a final volume of $6 \mu \mathrm{L}$. The ligation reaction is incubated at room temperature for 5-30 min.

5. Transform a $50 \mu \mathrm{L}$ aliquot of One Shot TOP10 chemically competent E. coli with $2 \mu \mathrm{L}$ of the TOPO cloning reaction following the manufacturer's instructions, and plate the cells onto LB plates containing $50 \mu \mathrm{g} / \mathrm{mL}$ kanamycin. Incubate overnight at $37^{\circ} \mathrm{C}$.

6. Select around ten positive colonies and check the presence of the insert by colony PCR using target-specific primers. Sequence the positive clones using the M13 forward and/or the M13 reverse primers, and confirm the expected insert sequence (see Note 4).

\subsubsection{Recombination into the destination vector and generation of the expression clones}

The entry clones generated in Subheading 3.1.1 have the att $\mathrm{L} 1$ and att $\mathrm{L} 2$ sites, so they are suitable for subsequent LR clonase reactions. The LR recombination reaction is performed to transfer the DNA fragment of interest into an attR-containing destination 
vector to create an attB- containing expression clone using the GATEWAY technology (Invitrogen).

We selected three different binary vectors to facilitate transgenic overexpression, RNAi silencing and localization of promoter-GUS expression. The three vectors contained the $a t t R$ sites and the DsRed marker gene for identification and selection of cotransformed hairy roots. The following vectors were selected: pUBIcGFP-DR (20) for overexpression (see Note 5), pK7GWIWG2_ II-RedRoot (http://gateway.psb.ugent .be) for RNAi silencing, and pBGWFS7::pAtUbq10::DsRed for promoter-GUS expression analysis (modified from Karimi, Inze and Depicker (21)) (see Note 6).

1. Set the LR clonase reaction in a low-retention $0.5 \mathrm{~mL}$ microcentrifuge tube at room temperature by mixing the following components: $1-7 \mu \mathrm{L}(50-150 \mathrm{ng})$ ENTRY vector containing the target fragment, $1 \mu \mathrm{L}(150 \mathrm{ng})$ destination vector and TE buffer ( $\mathrm{pH} 8)$ to a final volume of $8 \mu \mathrm{L}$.

2. Gently vortex the LR clonase II enzyme mix (Invitrogen), and add $2 \mu \mathrm{L}$ of it to the reaction mixture. After mixing thoroughly, incubate the reaction at room temperature for $1-2 \mathrm{~h}$.

3. To stop the reaction, add $1 \mu \mathrm{L}$ of the Proteinase $\mathrm{K}$ solution, and incubate the mixture at $37^{\circ} \mathrm{C}$ for $10 \mathrm{~min}$ at $37^{\circ} \mathrm{C}$.

4. Transform $2 \mu \mathrm{L}$ of the $\mathrm{LR}$ reaction into a $50 \mu \mathrm{L}$-vial of One Shot ${ }^{\circledR} c c d \mathrm{~B}$ Survival $^{\mathrm{TM}} 2 \mathrm{~T}^{\mathrm{R}}$ (Invitrogen) or E. coli $\mathrm{DB} 3.1$ chemically competent cells, which possess a ccdB-resistance mechanism, using a standard method.

5. Plate $1 / 10$ of the transformation reaction onto an LB agar plate containing 65 $\mu \mathrm{g} / \mathrm{mL}$ spectinomycin and $15 \mu \mathrm{g} / \mathrm{mL}$ streptomycin. Centrifuge the rest of the reaction at $13.000 \mathrm{xg}$ for 3 minutes, remove the supernatant, resuspend the pellet in $100 \mu \mathrm{L}$ of $\mathrm{LB}$ and plate it in another LB plate with the same antibiotics. Incubate the plates overnight at $37^{\circ} \mathrm{C}$.

6. Identify positive transformants by colony PCR and sequencing using target specific primers.

\subsubsection{A. rhizogenes Transformation with the Expression Clones}

The easiest method to transform A. rhizogenes with the binary vectors is electroporation. In this case, the empty or recombined binary vectors pUBIcGFP-DR, pK7GWIWG2_II-Red- Root and pBGWFS7::pAtUbq10::DsRed were introduced into A. rhizogenes MSU440 by electroporation. We explain below how to prepare $A$. rhizogenes electrocompetent cells and how to transform them.

1. Inoculate $A$. rhizogenes MSU440 into $5 \mathrm{ml} \mathrm{LB}$ medium with appropriate antibiotics $(65 \mu \mathrm{g} / \mathrm{mL}$ spectinomycin and $15 \mu \mathrm{g} / \mathrm{mL}$ streptomycin for the 
plasmids used here). Grow at $28^{\circ} \mathrm{C}, 180 \mathrm{rpm}$, to an $\mathrm{OD}_{600}=1$. It will take approximately 12 hours.

2. Transfer $200 \mathrm{~mL}$ of the fresh culture into $200 \mathrm{~mL}$ LB medium with appropriate antibiotics. Allow cells to grow at $28^{\circ} \mathrm{C}, 180 \mathrm{rpm}$, to an $\mathrm{OD}_{600}=0.5-0.6$. It will take at least 4-5-h.

3. Put the cell culture on ice for $15 \mathrm{~min}$ and transfer it into 4 prechilled $50 \mathrm{~mL}$ Falcon tubes.

4. Centrifuge $\left(10 \mathrm{~min}, 3000 \times \mathrm{g}, 4^{\circ} \mathrm{C}\right)$ the Falcon tubes, pour off the media and resuspend the cell pellet with $40 \mathrm{ml}$ of ice-cold and sterile deionized water (see Note 7).

5. Repeat step 4, but resuspending the pellet with $20 \mathrm{~mL}$ of ice-cold deionized water.

6. Repeat step 4 , but resuspending the pellet with $10 \mathrm{~mL}$ of ice-cold sterile $10 \%$ glycerol.

7. Mix the four fractions, centrifuge $\left(10 \mathrm{~min}, 3000 \mathrm{x} g, 4^{\circ} \mathrm{C}\right)$ the cell culture, pour off the media and resuspend the cell pellet with $1 \mathrm{~mL}$ of ice-cold and sterile $10 \%$ glycerol.

8. Aliquot the cells into $50 \mu \mathrm{L}$ vials. These aliquots can either be used directly for transformation or could be frozen immediately in liquid nitrogen and stored at $80^{\circ} \mathrm{C}$ for future use.

9. If competent cells from freezer stocks are used for transformation, allow them to thaw on ice.

10. Add 1-5 $\mu \mathrm{L}$ (100-500 ng) of plasmid and transfer the transformation reaction to a prechilled electroporation cuvette and keep it on ice for 10-15 min.

11. Insert the cuvette in the electroporator and apply and electroporation pulse according to the electroporator manufacturer's recommendations for Agrobacterium.

12. Add $1 \mathrm{~mL} \mathrm{LB}$ medium to the cuvette, and transfer the content into a $12 \mathrm{~mL}$ Falcon tube. Fill it up to $3 \mathrm{~mL}$ with LB medium and incubate for 3 hours at $28^{\circ} \mathrm{C}, 180 \mathrm{rpm}$.

13. Plate $1 / 10$ and the rest of the transformation reaction onto two different LB agar plates, both containing $150 \mu \mathrm{g} / \mathrm{mL}$ spectinomycin and $30 \mu \mathrm{g} / \mathrm{mL}$ streptomycin. Incubate at $28^{\circ} \mathrm{C}$ for 2 days.

14. Identify by PCR positive clones to be used in plant transformation 


\subsection{In vitro generation of composite plants}

Several protocols for A. rhizogenes- mediated transformation are available. For a particular plant species, different protocols can be appropriate, while certain protocols can be suitable for plants from different species. However, the basic principles behind each protocol are the same: (A) Suppression of root meristem activity to promote development of adventitious roots; and (B) inoculation of the A. rhizogenes culture to the wounded surface of the plant. Here, we will describe in detail the hairy root transformation method for tomato and will summarize alternative protocols and modifications performed when this procedure is applied to other plant species (Table 2) (see Note 8). An overview of the method presented in this chapter is provided in Figure 1.

Figure 1 highlights the important steps of the procedure which most easily achieved the highest transformation efficiencies. A. rhizogenes MSU440 cultures harbouring the corresponding overexpression, RNAi and promoter-GUS constructs, were used to transform S. lycopersicum plantlets according to a technique adapted from a previously described protocol (3). As a control, plants transformed with the corresponding empty vector were used (see Note 9).

1. Surface sterilized $S$. lycopersicum cv Moneymaker seeds by soaking for 5 min using $2.35 \% \mathrm{w} / \mathrm{v}$ sodium hypochlorite $(50 \% \mathrm{v} / \mathrm{v}$ commercial bleach) and then washed three times with sterile distilled water.

2. Subject the seeds to 1-day imbibition in distilled water in the dark at RT with slight shaking, in order to improve the germination percentage, speed and uniformity.

3. Place the seeds in sterile and sealed Petri dishes with wet filter paper. Incubate it in the dark at $25-28^{\circ} \mathrm{C}$ for 4 days.

4. After germination (Fig. 2A), place the germinated seeds on a filter paper on 0.5 $\times$ MS agar medium ( $0.8 \%$ agar) plates (Fig. 2B). The MS medium includes vitamins that allow favourable conditions at seedling emergence and during the first days following infection. The plates are sealed with stretch film ( see Note 10). Leave the germinated seeds to emerge in a growth chamber for 4 days at 24 ${ }^{\circ} \mathrm{C}$, with a $16 \mathrm{~h}$ light $/ 8 \mathrm{~h}$ dark photoperiod and $\sim 115 \mu \mathrm{mol} \mathrm{m}^{-2} \mathrm{~s}^{-1}$ of light intensity.

5. Remove the radicle and the bottom part of the hypocotyl from these 4-day-old seedlings, while maintaining the $1-\mathrm{cm}$ apical portion of the hypocotyl.

6. To generate hairy roots (genetically transformed), use a sterile syringe tip coated with transgenic A. rhizogenes to puncture the stem of the cutting 3-4 times. Alternatively, diagonally cut radicles can be coated with the A. rhizogenes culture. The Agrobacterium culture must be fresh and previously grown at $28^{\circ} \mathrm{C}$ for $48 \mathrm{~h}$ in LB Petri dishes. 
7. Keep the wounded seedlings on the same $0.5 \times \mathrm{MS}$ agar plates, and cover their hypocotyls with a humid filter paper strip to maintain moisture (Fig. 2C). Set the seedlings in a growth chamber for one week, under the same conditions as before.

8. Remove roots grown during the first week (adventitious laterals, nontransformed roots), and transfer the plantlets to $0.5 \times \mathrm{MS}$ agar medium $(0.8 \%$ agar) plates without vitamins in order to boost new root development.

9. During the following 3-4 weeks, weekly screen and remove DsRed-negative roots (non-cotransformed) by observation under a fluorescent stereomicroscope (Fig. 2D,E). For a good visualization of the roots it is necessary to previously remove the filter paper covering the roots in the laminar flow. In addition, under the Green lamp of the fluorescent stereomicroscope and using a red filter, you need to label differently the cotransformed and non-cotransformed roots, with a marker pen on the Petri dish lid (Fig. 2E). Then go back again to the laminar flow to remove the non-cotransformed hairy roots (see Note 11). Plantlets with at least one cotransformed hairy root (DsRed positive root) must be transferred to $0.5 \times \mathrm{MS}$ agar medium $(0.8 \%$ agar $)$ with vitamins.

10. When the seedlings are enough vigorous (Fig. 2F), transplant to pots those seedlings with selected DsRed-positive roots and allow them to grow in a growth chamber. 


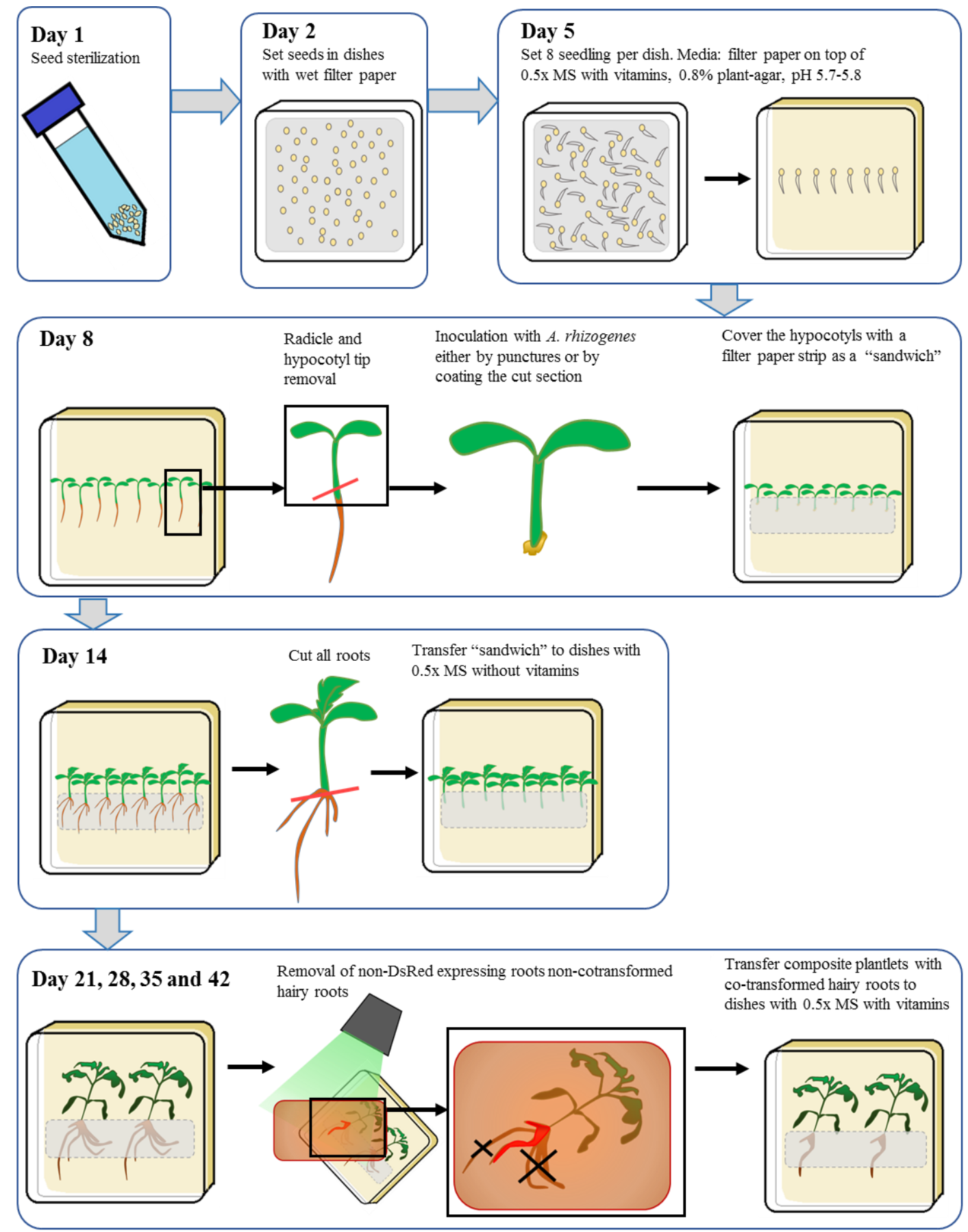

Figure 1. Schematic representation of the time-line required for the generation of composite tomato plants. 
Table 2

Composite plant generation protocols and studies related to AM symbioses that use those protocols.

\begin{tabular}{|c|c|c|c|}
\hline \multirow[t]{2}{*}{ Protocol } & \multicolumn{3}{|c|}{$\begin{array}{l}\text { Studies related to AM symbiosis using the } \\
\text { protocol }\end{array}$} \\
\hline & $\begin{array}{l}\text { Studied genel } \\
\text { promoter/ } \\
\text { miRNA }\end{array}$ & $\begin{array}{l}\text { Modification with respect to the original } \\
\text { protocol }\end{array}$ & Ref. \\
\hline $\begin{array}{l}\text { Protocol of Quandt et al. (24): } \\
\text { Species: Vicia hirsuta } \\
\text { A. rhizogenes strain: ARqua2 } \\
\text { Mode of inoculation: Two days after germination, one side of the } \\
\text { epicotyl was stabbed three times proximal to the seed with the } \\
\text { needle of an Agrobacterium-containing syringe. } \\
\text { - Marker of cotransformed hairy roots: GUS } \\
\text { - Cotransformation efficiency: } 88 \% \text { of roots }\end{array}$ & MtSUC1 & ARqua1 & (25) \\
\hline $\begin{array}{l}\text { Protocol of Diouf et al. (26): } \\
\text { - Species: Casuarina glauca } \\
\text { - A. rhizogenes strain: A4RS } \\
\text { - Mode of inoculation: Hypocotyl wounded with a needle (1 month } \\
\text { after germination) } \\
\text { - Marker of cotranformed hairy roots: GUS } \\
\text { - Cotransformation efficiency: } 65-75 \% \text { of hypocotyls }\end{array}$ & CgSymRK & -Selection by GFP & (26) \\
\hline \multirow{12}{*}{$\begin{array}{l}\text { Protocol of Boisson-Dernier et al. (3): } \\
\text { - Species: Medicago truncatula } \\
\text { - A. rhizogenes strain: ARqual } \\
\text { - Mode of inoculatfion: A. rhizogenes inoculation directly onto } \\
\text { seedling radicles that had been freshly sectioned to remove the tip } \\
\text { - Marker of cotransformed hairy roots: GUS } \\
\text { - Cotransformation efficiency: } 60 \% \text { of plants and } 66 \% \text { of roots }\end{array}$} & $p M t P T 4$ & - & (27) \\
\hline & $\begin{array}{l}p M t C e l 1 \text { and } \\
\text { pMtSCP1 }\end{array}$ & - & (28) \\
\hline & pMtENOD11 & & (29) \\
\hline & MtLec5 & -protein fusion-GFP & (30) \\
\hline & OsPollux & $\begin{array}{l}\text { - Cotransformed roots selected based on } \\
\text { OsPollux qPCR }\end{array}$ & (31) \\
\hline & Vapyrin & -Cotransformation marker: DsRED & (16) \\
\hline & STR & & (17) \\
\hline & $\begin{array}{l}\text { miR171h and } \\
\text { NSP2 } m R N A\end{array}$ & -Cotransformation marker: DsRED & (32) \\
\hline & $\begin{array}{l}\text { MtROP9 } \\
\text { mCherry } \\
\text { labelled } \\
\text { proteins }\end{array}$ & $\begin{array}{l}\text {-Cotransformation marker: DsRED } \\
\text { - Cotransformed roots selected based on } \\
\text { mCherry fluorescence }\end{array}$ & $\begin{array}{l}(33) \\
(34)\end{array}$ \\
\hline & miR393 & -Cotransformation marker: DsRED & (35) \\
\hline & $\begin{array}{l}\text { MIG1 and } \\
\text { DELLA }\end{array}$ & -Cotransformation marker: DsRED & (15) \\
\hline & $\begin{array}{l}\text { RAD1 } \\
\text { WRI5a }\end{array}$ & $\begin{array}{l}\text {-Cotransformation marker: DsRED } \\
\text { - Cotransformed roots selected based on } \\
\text { fluorescence }\end{array}$ & (36) \\
\hline \multirow{4}{*}{$\begin{array}{l}\text { Protocol of Díaz et al. (38): } \\
\text { Species: Lotus japonicus } \\
\text { A. rhizogenes strain: LBA1334 } \\
\text { - Mode of inoculatfion: Agrobacterium is streaked on the hypocotyls } \\
\text { from 4-day old seedlings about } 2-3 \mathrm{~mm} \text { below the point of insertion } \\
\text { of the cotyledons, and the hypocotyls are sectioned in the middle of } \\
\text { the zone streaked with Agrobacterium. } \\
\text { - Marker of cotransformed hairy roots: GUS } \\
\text { - Cotransformation efficiency } 50-75 \% \text { of roots were transformed } \\
\text { roots. } 78-85 \% \text { of plants had transformed roots. }\end{array}$} & SymRK & - A. rhizogenes strain AR1193 & (39) \\
\hline & SymRK & $\begin{array}{l}\text { - A. rhizogenes strains AR1193 and AR10 } \\
\text { - Cotransformed roots selected based on km } \\
\text { resistance }\end{array}$ & $(40)$ \\
\hline & ССаМK & $\begin{array}{l}\text { - A. rhizogenes strain AR1193 } \\
\text { - Cotransformation marker: GFP }\end{array}$ & (41) \\
\hline & CCaMK & - Cotransformation markers: GFP or DsRed & (42) \\
\hline $\begin{array}{l}\text { Protocol of Estrada-Navarrete et al. (43): } \\
\text { Species: Phaseolus vulgaris } \\
\text { A. rhizogenes strain: K599 } \\
\text { - Mode of inoculatfion: Wounding with A. rhizogenes at the } \\
\text { cotyledon node of plantlets growing in vermiculite ( } 3 \text { days after } \\
\text { germination) } \\
\text { - Marker of cotransformed hairy roots: GFP } \\
\text { - Cotransformation efficiency: } 70-90 \%\end{array}$ & RbohB & - & (44) \\
\hline $\begin{array}{l}\text { Protocol of Ho-Plágaro et al. (19): } \\
\text { - Species: Solanum lycopersicum } \\
\text {. A. rhizogenes strain: MSU440 }\end{array}$ & SIGRAS & - & (4) \\
\hline $\begin{array}{l}\text { - Mode of inoculatfion: punctured or coated-inoculated seedlings } 3 \\
\text { days after germination }\end{array}$ & SIPtc52 & - & (45) \\
\hline $\begin{array}{l}\text { - Marker of cotransformed hairy roots: DsRed } \\
\text { Cotransformation efficiency: } 93 \% \text { of plantlets }\end{array}$ & PHYTOGB1 & - & (46) \\
\hline
\end{tabular}



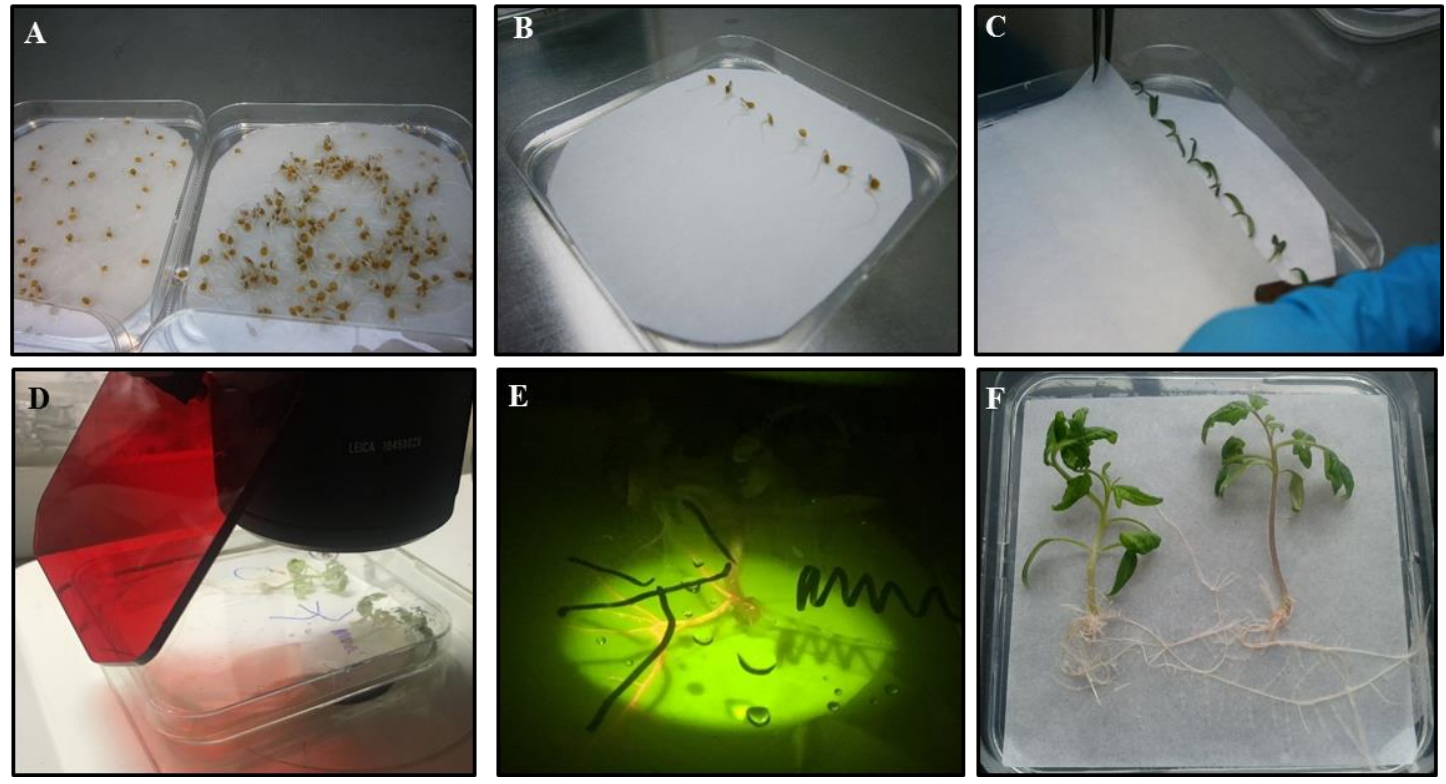

Figure 2. Illustration of some steps in the process of composite tomato plantlets generation. Germinated seeds (A) and their transfer to Petri dishes with MS media (B). Setting of a filter paper strip covering hypocotyls after A. rhizogenes inoculation (C). Observation and labelling of DsRed-positive roots under a green fluorescent lamp (D-E). Resulting strong tomato seedlings ready to be transferred to pots $(\mathrm{F})$.

\subsection{AM inoculation and plant growth in pots}

1. Fill the $500-\mathrm{mL}$ pots with an autoclave-sterilized $\left(20 \mathrm{~min}\right.$ at $\left.120^{\circ} \mathrm{C}\right)$ mixture of expanded clay, washed vermiculite and coconut fibre (2:2:1, by volume). For the AM inoculated plants, additionally add a piece of monoxenic culture in Gel-Gro medium containing $50 \mathrm{R}$. irregularis (DAOM 197198) spores and infected carrot roots as previously described (19). Set the plants in a growth chamber (day: night cycle, $16 \mathrm{~h}, 24{ }^{\circ} \mathrm{C} ; 8 \mathrm{~h}, 20{ }^{\circ} \mathrm{C}$; relative humidity $50 \%$ ). As hairy root tomato plantlets strongly suffer during transfer from in vitro to pot culture, place plastic glasses or humidity domes on top of the plants and spray them with water every 2 days to maintain moisture and to prevent wilting during the first weeks.

2. One week after planting and weekly thereafter, add $20 \mathrm{ml}$ of a modified Long Ashton nutrient solution containing $25 \%$ of the standard phosphorus (P) concentration to the pots (23), as low phosphate conditions have been shown to stimulate hyphal branching, consequently improving the rate of colonization by the AM fungi $(47,48)$.

3. Harvest plants at different times after inoculation. Wash and rinse the root system with tap water. Screen and remove DsRed-negative roots (nontransformed laterals or non-cotransformed hairy roots) by observation under a fluorescent Leica M165F stereomicroscope. 


\subsection{Confirmation of transformed nature of hairy roots}

\subsection{Selection of DsRed Hairy roots}

Use a fluorescence stereo-microscope equipped with green fluorescent lamp and a redorange filter to visualize the cotransformed hairy roots, which express the red fluorescent protein marker DsRED (Fig. 3), a highly reliable marker for the selection of transgenic roots $(49,50)$.

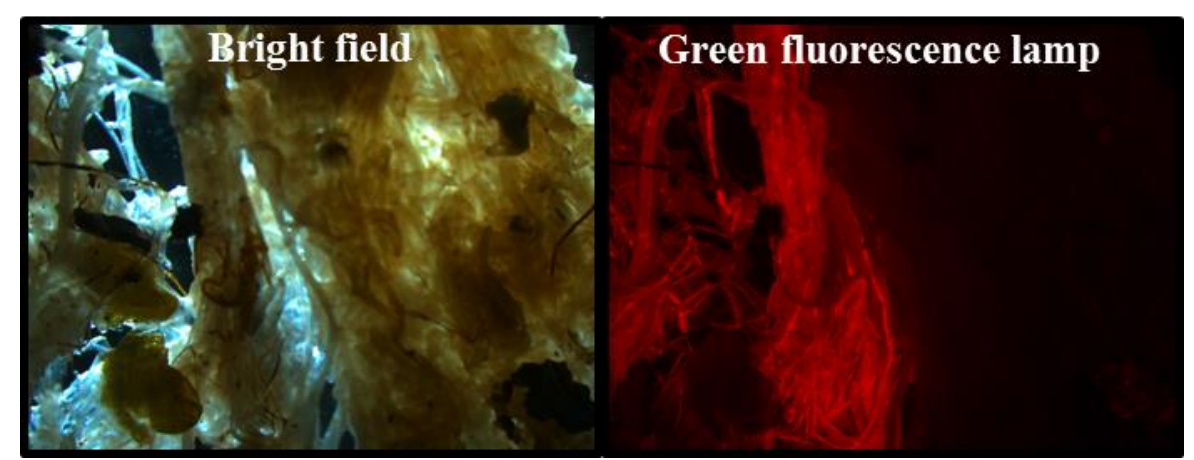

Figure 3. Screening of cotransformed hairy roots expressing the DsRed marker gene in adult composite tomato plants. Root system from a tomato composite adult plant exposed to bright field (left image) and to a green fluorescent lamp followed by visualization through a red-orange photography filter (right image), which allows to easily detect the DsRed positive roots.

\subsubsection{Quantification of the level of gene silencing or overexpression}

The level of gene silencing or overexpression is measured through qPCR analysis in representative samples from root systems of at least six different composite plants (see Note 12).

1. Harvest $0.2 \mathrm{~g}$-samples, freeze the tissue with liquid nitrogen and store the samples at $-80{ }^{\circ} \mathrm{C}$ until proceeding for RNA isolation.

2. Isolate total RNA from the 0.2 g-samples using the RNeasy Plant Mini Kit (Qiagen, Hilden, Germany) following the manufacturer's instructions.

3. Treat the isolated RNA with RNase-Free DNase to minimize genomic DNA carryover, which will obscure your gene expression values.

4. Use $1 \mu \mathrm{g}$ of DNAse-treated RNA for reverse-transcription into cDNA with the iScriptTM cDNA synthesis kit (Bio-Rad, Hercules, CA, USA), following the supplier's protocol.

5. Perform a qPCR with specific primers to measure expression of the corresponding gene that is expected to be silenced or overexpressed (see Note 13). In triplicate, prepare a $20 \mu \mathrm{L}$ qPCR reaction containing $1 \mu \mathrm{L}$ of diluted cDNA (1:10), $10 \mu \mathrm{L} 2 \times$ SYBR Green Supermix (Bio-Rad, Hercules, CA, USA) and $200 \mathrm{nM}$ of each primer using a 96-well plate. 
6. Determine the threshold cycle $(\mathrm{Ct})$ for each triplicate and calculate the corresponding relative transcription levels.

7. Normalize the $\mathrm{Ct}$ values of the target gene to the $\mathrm{Ct}$ value of a reference gene. For tomato, the LeEF-1 $\alpha$ (accession number X14449) housekeeping gene is a good choice. For qPCR amplification of LeEF-1 $\alpha$ use primers 5'GGTGGCGAGCATGATTTTGA-3'and 5'CGAGCCAACCATGGAAAACAA-3'.

8. Express the qPCR data for the target gene as relative expression with respect to the control treatment (non-AM inoculated roots) to which an expression value of 1 is assigned. If any of the composite plants show a significant level of overexpression or silencing, the promoter driving the transgene expression may not be suitable (see Note 14).

\subsection{Localization of promoter expression and the AM fungus}

AM inoculated transgenic roots carrying the promoter-GUS fusion are subjected to GUS staining based on a technique earlier developed by Jefferson (51), in order to check in what cells is expressed the corresponding promoter. Use non-inoculated transgenic roots as a control.

1. Vacuum-infiltrate the hairy roots with a GUS staining solution for $30 \mathrm{~min}$ to improve substrate penetration.

2. Incubate the tissues in the dark at $37{ }^{\circ} \mathrm{C}$ from $1 \mathrm{~h}$ to overnight or until staining is satisfactory.

3. For co-staining of the AM fungus, embed the GUS-stained hairy roots in hot $\left(\sim 60^{\circ} \mathrm{C}\right)$ liquid $4 \%$ agarose in PBS $1 \mathrm{X}$.

4. Cut $60 \mu \mathrm{m}$ longitudinal sections on a vibratome following manufacturer instructions.

5. Vacuum-infiltrate the root sections with $10 \mu \mathrm{g} \mathrm{ml}{ }^{-1}$ WGA-Alexa Fluor 488 conjugate (Molecular Probes, Eugene, Oreg., USA) in PBS 1X for $20 \mathrm{~min}$ in the dark.

6. Wash cuttings with PBS 1X: immerse the cuttings in a Petri dish with PBS $1 \mathrm{X}$ under a fluorescent stereomicroscope, and take them out when you observe that the green fluorescence is restricted to the colonized regions.

7. Mount the root fragments on a slide with PBS $1 X$ and a coverslip.

8. Visualize the roots with an inverted fluorescent microscope (Figure 4). 


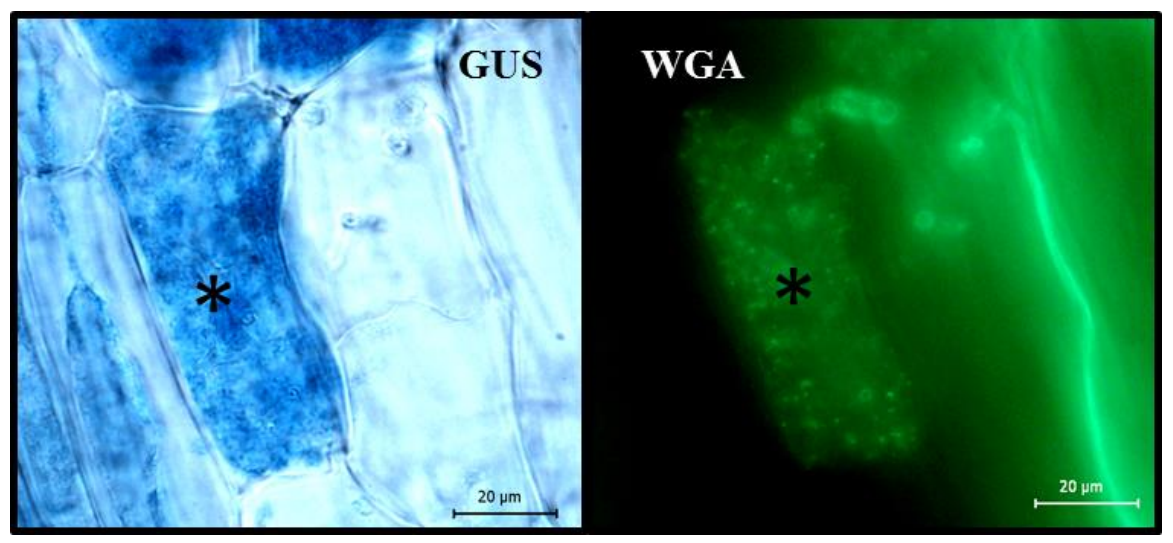

Figure 4. Localization of promoter expression and the AM fungus. GUS (left image) and WGA-Alexa Fluor 488 (right image) co-staining of mycorrhizal hairy roots transformed with the SIPT4 promoter-GUS fusion in order to visualize both the cells expressing the GUS promoter and the AM fungus, respectively. In this case, as previously described, the SIPT4 promoter is expressed in the arbuscule-containing cells (52), labelled with an asterisk.

\subsection{Characterization of symbiotic phenotype resulting from alterations of plant host genes}

\subsubsection{Trypan blue staining for estimation of AM colonization}

The non-vital trypan blue staining is used for an overview of the mycorrhizal colonization phenotype and for the estimation of AM colonization and mycorrhizal parameters. The protocol is based on the method described by Phillips and Hayman (53) with some modifications:

1. Clear root segments with $10 \% \mathrm{KOH}$ for $10 \mathrm{~min}$ in a boiling water bath. This removes the cell root cytoplasm and most of the nuclei, and the roots become very clear with the vascular cylinder distinctly visible.

2. Rinse the roots several times with tap water

3. Acidify the roots by incubation with $0.1 \mathrm{~N} \mathrm{HCl}$ for $3 \mathrm{~min}$.

4. Remove excess of $\mathrm{HCl}$ and stain them by simmering for $10-15$ min with $0.05 \%$ trypan blue in lactic acid.

5. Remove excess stain by replacing the staining solution with clear lactic acid.

6. Evaluate mycorrhiza development in terms of percentage of mycorrhizal root length by the gridline intersect method described by Giovannetti and Mosse (54). For this purpose, spread out the root sample in a grid-lined Petri dish, and scan under a stereomicroscope vertical and horizontal gridlines, recording the presence or absence of infection at each point where the roots intersect a line. At least 200 root-gridline intersects must be recorded.

7. For determination of the intensity and frequency of root cortex colonization, according to the procedure of Trouvelot (55), prepare three microscope slides per biological replicate, each slide containing thirty $1-\mathrm{cm}$ root pieces. Observe 
the roots with a light microscope and rate each root according to its mycorrhizal intensity (five classes: $0 \%,<1 \%,<10 \%,<50 \%,>50 \%$ y $>90 \%$ ) or to its arbuscule abundance (four classes: none/few/frequent/abundant). Determine the different mycorrhizal parameters using MYCOCALC software (http://www.dijon.inra.fr/mychintec/Mycocalc-prg/download.html): Frequency of mycorrhiza in the root system $(\mathrm{F} \%)$; intensity of mycorrhizal colonization in the entire root system (M\%) or in mycorrhizal root fragments $(\mathrm{m} \%)$; and arbuscule abundance in the entire root system (A\%) or in mycorrhizal fragments $(\mathrm{a} \%)$.

\subsubsection{WGA-fluorescent staining for arbuscule morphology analysis}

Wheat Germ Agglutinin (WGA)-Alexa Fluor 488 is a lectin that has a strong affinity for oligomers and polymers of $\mathrm{N}$-acetylglucosamine residues, especially chitin (56) on the hyphal cell wall, allowing a detailed imaging of arbuscules through confocal microscopy.

1. Place the roots in $50 \%$ ethanol for 4 hours to overnight.

2. Remove ethanol.

3. Incubate the roots in $20 \% \mathrm{KOH}$ for 2-3 days.

4. Wash the roots with distilled water.

5. Incubate the roots in $\mathrm{HCl} 0.1 \mathrm{M}$ for 1-2 hours.

6. Rinse the roots with Milli-Q $\mathrm{H}_{2} \mathrm{O}$ and let at least 6 hours in the staining solution of WGA $0.2 \mu \mathrm{g} / \mathrm{mL}$ in PBS $1 X$.

7. Wash roots with PBS $1 X$.

8. Mount root segments on microscope glass slide with PBS $1 X$ and a coverslip.

9. Visualize arbuscule morphology and intraradical hyphae using a confocal microscope and exciting the sample with an argon blue laser.

\subsubsection{Analysis of gene expression of AM-marker genes}

Several marker genes of arbuscule functionality can be measured by qPCR, in the same way as described in Subheading 2.4.2. Analysis of alterations in expression of AMinduced marker genes associated to different aspects of arbuscule activity may be useful to elucidate the possible functions of the specifically silenced or overexpressed gene. Genes used are usually putative orthologues to previously described markers of arbuscule functioning, such as:

- $\quad R A M 1$, a central regulator of arbuscule branching that modulates arbusculerelated gene expression $(57,58)$. 
- EXO84 and EXO70i, implicated in the exocytosis program associated with arbuscule development $(59,60)$. These genes, together with Vapyrin $(16,61)$, are involved in cellular rearrangements and membrane trafficking.

- RAM2, encoding an AM-inducible glycerol-3 phosphate-O-acyltransferase (GPAT) that is involved in the fatty acid biosynthesis and required to support a full arbuscule development (62).

- STR gene, essential for arbuscule development and encoding a periarbuscular membrane $\mathrm{ABC}$ transporter required for arbuscule functionality that mediates lipid transfer from the plant to the fungus $(17,62)$.

- PT4 and AMT2.2 genes, encoding specialized periarbuscular membrane transporters of minerals (phosphate and ammonium, respectively) from the AM fungus to the root $(27,63)$.

\section{Notes}

1. When designing primers for amplification of the RNA interference fragment, it is very important to make sure that they specifically amplify the target gene, so use primers that bind to unique regions of the corresponding gene. Otherwise, other closely related genes of the same gene family can be up/down-regulated. In addition, in the case of the RNAi fragment, it is recommended to test the degree of RNA silencing from a few 400- to 500-bp target sequences and select the most efficient one in producing functional silencing.

2. A blunt-end-generating DNA polymerase such as the iProof High-Fidelity DNA Polymerase (BioRad) must be used for amplification of the DNA fragment that is going to be cloned into the pENTR/D-TOPO vector. Do not use a Taq polymerase, as it possesses a non-template-dependent terminal transferase activity that adds a single deoxyadenosine (A) to the $3^{\prime}$ ends of the PCR products.

3. When excising a gel band, take in account that short wavelength UV light damages the DNA and decreases its cloning efficiency, so use the minimal exposure time, and use long wavelength UV light $(365 \mathrm{~nm})$ if possible. Alternatively, we can avoid DNA damage derived from UV exposure by using a blue light transilluminator or incorporating crystal violet to the gel that allows visualization of the PCR band during gel migration.

4. Although PCR products are directionally cloned into the pENTR/D-TOPO with efficiencies above $90 \%$ due to the 5' CACC overhang, we must confirm the correct orientation when sequencing the positive clones. An exception is the case of the RNAi hairpin constructs, where directionality is not essential. 
5. The pUBIcGFP-DR vector (20) used for gene overexpression is also suitable for subcellular protein localization. By cloning a transgene lacking the 3'stop codon, it will be overexpressed the corresponding fusion protein with a $3^{\prime} \mathrm{GFP}$ tag. However, in our experience, this approach is not successful when working with tomato roots because of the strong green autofluorescence detectable at $488 \mathrm{~nm}$ in tomato roots.

6. For promoter-GUS expression localization studies, the DsRed fluorescent

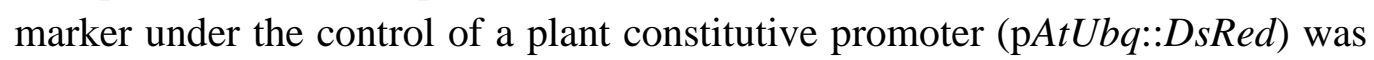
included in the pBGWFS7 vector (21), in order to allow selection of transformed roots. For this purpose the In-Fusion cloning strategy was followed. The pBGWFS7 vector was linearized by restriction enzyme digestion with $\mathrm{KpnI}$ at the insertion site and the $\mathrm{p} A t U b q:: D s R e d$ fragment was amplified using the PCR In-Fusion primers 5' CTAGAGGATCCCCGGCTTACATTCTGAGCCTCTTTCC-3’ ${ }^{\prime}$ and 5'GATAATTCGAGCTCGTGATGGATATCTGCAGAATTCG-3'. The InFusion cloning kit (Clontech) was used to fuse both fragments.

7. The repeated rounds of centrifugation and washes in decreasing volumes of sterile cold water are performed in order to remove all salts, and replace the solution with non-conductive distilled water. If salts are not properly removed from the solution, they can create a strong electrical current (electrical sparkling) during the electroporation pulse that will kill the cells. At this step, make sure that centrifugations are not performed at too high speed, as it will rupture the cells.

8. The main protocols used for composite plant generation are listed in Table 2. In addition publications using those protocols for the study of cell biology or gene functions associated with AM symbiosis are also shown.

9. When selecting the plant material used as the wild-type phenotype control for the gene overexpression or downregulation experiments, two options arise. The first option is to use as an internal control those non-cotransformed roots (DsRed negative roots) belonging to the same composite plant, as gene overexpression/silencing does not spread systematically to non-cotransformed roots $(49,64)$. This is possible, considering that cotransformed and wild-type roots are morphologically indistinguishable and that they interact with AM fungi in the same way, as demonstrated by Mrosk et al. (65), who did not detect general differences in the degree of mycorrhization, the life span an morphology of arbuscules, the structure of the plant cortex arbuscule containing cells, the transcript levels of AM-associated genes, and the metabolite accumulation of AM-induced isoflavonoids and AM-specific apocarotenoids. However, we must not discard possible undetected alterations affecting the mycorrhizal symbiosis in the cotransformed roots due to the expression of the rol genes that disturb plant hormonal balance $(66,67)$ and/or the DsRed fluorescent protein marker overproduction. Taking in account this possibility, alternatively we can use as a 
control hairy roots from control composite plants transformed with the corresponding empty vector that are DsRed positive and also express the rol genes.

10. The use of stretch film to seal the plates instead of parafilm facilitates gas exchange. If parafilm is used, several incisions have to be made in the parafilm to allow gas exchange. Alternatively, the use of surgical tape has been also proved to be successful (50).

11. Although incorporation of the corresponding antibiotics or herbicides to plates favours the selective growth of cotransformed roots, we do not recommended it, as, in our experience it hampers health of shoots. Selection of cotransformed roots expressing the DsRed marker gene and continuous removal of nontransgenic roots is a better option for plant fitness, despite requiring a slightly higher handling. In addition, the DsRed marker allows selection of transgenic roots when plants are later grown in ex-vitro conditions, when antibiotics or herbicides cannot be used for selection.

12. Each independent root arises from an independent transformation event and some may have a mosaic pattern of expression of the inserted construct. Then, ideally, the degree of gene overexpression or silencing should be determined in an individual root. However, this is often not possible because an individual root does not usually reach the minimum weight $(0.2 \mathrm{~g})$ required for RNA extractions and other analyses. In this manner, to estimate the overall level of gene overexpression or downregulation, we use as a sample a pool of transformed roots belonging from the same plant.

13. When analysing the level of silencing in the RNAi roots by qPCR, make sure that the qPCR primers amplify a region of the downregulated gene that is not included in the hairpin RNAi fragment. Otherwise, we will observe an increased amplification of the overexpressed hairpin RNAi.

14. Selection of the promoter driving transgene expression is an important issue with regards to mycorrhization and the concerned plant species. In our experience, the maize ubiquitin promoter (UBIL) and the CaMV 35S promoter (p35S) driven gene overexpression and hairpin RNAi are good choices for transformation of mycorrhizal tomato roots. However, for example, $\mathrm{p} 35 \mathrm{~S}$ is not suitable to determine gene function in infected cells of Medicago nodules (68). 


\section{Acknowledgements}

This work was supported by grants from the Comisión Interministerial de Ciencia y Tecnología (CICYT) and Fondos Europeos de Desarrollo Regional (FEDER) through the Ministerio de Economía, industria y Competitividad in Spain (AGL2014-52298-P, AGL2017-83871-P).

\section{References}

1. F. C. Stewart, F. M. Rolfs, F. H. Hall, A fruit-disease survey of western New York in 1900. (New York Agricultural Experiment Station, 1900).

2. D. Tepfer, Transformation of several species of higher plants by Agrobacterium rhizogenes: sexual transmission of the transformed genotype and phenotype. Cell 37, 959-967 (1984).

3. A. Boisson-Dernier, M. Chabaud, F. Garcia, G. Bécard, C. Rosenberg, D. G. Barker, Agrobacterium rhizogenes-transformed roots of Medicago truncatula for the study of nitrogen-fixing and endomycorrhizal symbiotic associations. Mol. Plant-Microbe Interact. 14, 695-700 (2001).

4. T. Ho-Plágaro, N. Molinero-Rosales, D. F. Flores, M. V. Díaz, J. M. García-Garrido, Identification and expression analysis of GRAS transcription factor genes involved in the control of arbuscular mycorrhizal development in tomato. Front. Plant Sci. 10, (2019).

5. I. Iberkleid, P. Vieira, J. de Almeida Engler, K. Firester, Y. Spiegel, S. B. Horowitz, Fatty acidand retinol-binding protein, Mj-FAR-1 induces tomato host susceptibility to root-knot nematodes. PloS one 8, e64586 (2013).

6. B. Chinnapandi, P. Bucki, S. Braun Miyara, SIWRKY45, nematode-responsive tomato WRKY gene, enhances susceptibility to the root knot nematode; M. javanica infection. Plant Signal Behav 12, e1356530 (2017).

7. S. Runo, S. Macharia, A. Alakonya, J. Machuka, N. Sinha, J. Scholes, Striga parasitizes transgenic hairy roots of Zea mays and provides a tool for studying plant-plant interactions. Plant Methods 8, 20 (2012).

8. S. Srivastava, A. K. Srivastava, Hairy root culture for mass-production of high-value secondary metabolites. Crit. Rev. Biotechnol. 27, 29-43 (2007).

9. M. Kumari, S. Chandra, Secondary Metabolite Production in Transformed Cultures: Stevioside Glycosides Production from Stevia rebaudiana Hairy Root Cultures. Transgenesis and Secondary Metabolism, 103-121 (2017).

10. M. A Talano, A. Laura Wevar Oller, P. S Gonzalez, E. Agostini, Hairy roots, their multiple applications and recent patents. Recent patents on biotechnology 6, 115-133 (2012).

11. P. D. Gurusamy, H. Schäfer, S. Ramamoorthy, M. Wink, Biologically active recombinant human erythropoietin expressed in hairy root cultures and regenerated plantlets of Nicotiana tabacum L. PloS one 12, $\mathrm{e} 0182367$ (2017).

12. M.-D. Chilton, D. A. Tepfer, A. Petit, C. David, F. Casse-Delbart, J. Tempé, Agrobacterium rhizogenes inserts T-DNA into the genomes of the host plant root cells. Nature 295, 432-434 (1982). 
13. O. Nilsson, O. Olsson, Getting to the root: the role of the Agrobacterium rhizogenes rol genes in the formation of hairy roots. Physiol. Plant. 100, 463-473 (1997).

14. T. Tzfira, V. Citovsky, Partners-in-infection: host proteins involved in the transformation of plant cells by Agrobacterium. Trends Cell Biol. 12, 121-129 (2002).

15. C. Heck, H. Kuhn, S. Heidt, S. Walter, N. Rieger, N. Requena, Symbiotic fungi control plant root cortex development through the novel GRAS transcription factor MIG1. Curr. Biol. 26, 2770-2778 (2016).

16. N. Pumplin, S. J. Mondo, S. Topp, C. G. Starker, J. S. Gantt, M. J. Harrison, Medicago truncatula Vapyrin is a novel protein required for arbuscular mycorrhizal symbiosis. Plant J. 61, 482-494 (2010).

17. Q. Zhang, L. A. Blaylock, M. J. Harrison, Two Medicago truncatula half-ABC transporters are essential for arbuscule development in arbuscular mycorrhizal symbiosis. Plant Cell 22, 1483-1497 (2010).

18. G.-B. Kim, S.-U. Son, H.-J. Yu, J.-H. Mun, MtGA2ox10 encoding C20-GA2-oxidase regulates rhizobial infection and nodule development in Medicago truncatula. Scientific reports 9, 5952 (2019).

19. T. Ho-Plágaro, R. Huertas, M. I. Tamayo-Navarrete, J. A. Ocampo, J. M. García-Garrido, An improved method for Agrobacterium rhizogenes-mediated transformation of tomato suitable for the study of arbuscular mycorrhizal symbiosis. Plant Methods 14, 34 (2018).

20. I. S. Kryvoruchko, S. Sinharoy, I. Torres-Jerez, D. Sosso, C. I. Pislariu, D. Guan, J. Murray, V. A. Benedito, W. B. Frommer, M. K. Udvardi, MtSWEET11, a Nodule-Specific Sucrose Transporter of Medicago truncatula. Plant Physiol. 171, 554-565 (2016).

21. M. Karimi, D. Inze, A. Depicker, GATEWAY vectors for Agrobacterium-mediated plant transformation. Trends Plant Sci. 7, 193-195 (2002).

22. T. Murashige, F. Skoog, A revised medium for rapid growth and bio assays with tobacco tissue cultures. Physiol. Plant. 15, 473-497 (1962).

23. E. J. Hewitt, Sand and water culture methods used in the study of plant nutrition. (Commenwealth Agricultural Bureaux, 1966).

24. H. J. Quandt, A. Pühler, I. Broer, Transgenic root nodules of Vicia hirsuta: a fast and efficient system for the study of gene expression in indeterminate-type nodules. Mol. Plant Microbe Interact. 6, 699-706 (1993).

25. N. Hohnjec, A. M. Perlick, A. Pühler, H. Küster, The Medicago truncatula sucrose synthase gene MtSucS1 is activated both in the infected region of root nodules and in the cortex of roots colonized by arbuscular mycorrhizal fungi. Mol. Plant-Microbe Interact. 16, 903-915 (2003).

26. D. Diouf, H. Gherbi, Y. Prin, C. Franche, E. Duhoux, D. Bogusz, Hairy root nodulation of Casuarina glauca: a system for the study of symbiotic gene expression in an actinorhizal tree. Mol. Plant Microbe Interact. 8, 532-537 (1995).

27. M. J. Harrison, G. R. Dewbre, J. Liu, A phosphate transporter from Medicago truncatula involved in the acquisition of phosphate released by arbuscular mycorrhizal fungi. Plant Cell 14, 24132429 (2002).

28. J. Liu, L. A. Blaylock, G. Endre, J. Cho, C. D. Town, K. A. VandenBosch, M. J. Harrison, Transcript profiling coupled with spatial expression analyses reveals genes involved in distinct developmental stages of an arbuscular mycorrhizal symbiosis. Plant Cell 15, 2106-2123 (2003).

29. A. Boisson-Dernier, A. Andriankaja, M. Chabaud, A. Niebel, E.-P. Journet, D. G. Barker, F. de Carvalho-Niebel, MtENOD11 gene activation during rhizobial infection and mycorrhizal arbuscule 
development requires a common AT-rich-containing regulatory sequence. Mol. Plant-Microbe Interact. 18, 1269-1276 (2005).

30. A. Frenzel, N. Tiller, B. Hause, F. Krajinski, The conserved arbuscular mycorrhiza-specific transcription of the secretory lectin MtLec5 is mediated by a short upstream sequence containing specific protein binding sites. Planta 224, 792-800 (2006).

31. C. Chen, C. Fan, M. Gao, H. Zhu, Antiquity and function of CASTOR and POLLUX, the twin ion channel-encoding genes key to the evolution of root symbioses in plants. Plant Physiol. 149, 306-317 (2009).

32. D. Lauressergues, P. M. Delaux, D. Formey, C. Lelandais-Brière, S. Fort, S. Cottaz, G. Bécard, A. Niebel, C. Roux, J. P. Combier, The microRNA miR171h modulates arbuscular mycorrhizal colonization of Medicago truncatula by targeting NSP2. Plant J. 72, 512-522 (2012).

33. L. M. Kiirika, H. F. Bergmann, C. Schikowsky, D. Wimmer, J. Korte, U. Schmitz, K. Niehaus, F. Colditz, Silencing of the Racl GTPase MtROP9 in Medicago truncatula stimulates early mycorrhizal and oomycete root colonizations but negatively affects rhizobial infection. Plant Physiol. 159, 501-516 (2012).

34. S. Ivanov, M. J. Harrison, A set of fluorescent protein-based markers expressed from constitutive and arbuscular mycorrhiza-inducible promoters to label organelles, membranes and cytoskeletal elements in Medicago truncatula. Plant J. 80, 1151-1163 (2014).

35. M. Etemadi, C. Gutjahr, J.-M. Couzigou, M. Zouine, D. Lauressergues, A. Timmers, C. Audran, M. Bouzayen, G. Bécard, J.-P. Combier, Auxin perception is required for arbuscule development in arbuscular mycorrhizal symbiosis. Plant Physiol. 166, 281-292 (2014).

36. T. Rey, M. Bonhomme, A. Chatterjee, A. Gavrin, J. Toulotte, W. Yang, O. André, C. Jacquet, S. Schornack, The Medicago truncatula GRAS protein RAD1 supports arbuscular mycorrhiza symbiosis and Phytophthora palmivora susceptibility. J. Exp. Bot. 68, 5871-5881 (2017).

37. Y. Jiang, Q. Xie, W. Wang, J. Yang, X. Zhang, N. Yu, Y. Zhou, E. Wang, Medicago AP2domain transcription factor WRI5a is a master regulator of lipid biosynthesis and transfer during mycorrhizal symbiosis. Mol. plant 11, 1344-1359 (2018).

38. C. L. Díaz, M. Grønlund, H. R. Schlaman, H. P. Spaink, in Lotus japonicus handbook. (Springer, 2005), pp. 261-277.

39. H. Gherbi, K. Markmann, S. Svistoonoff, J. Estevan, D. Autran, G. Giczey, F. Auguy, B. Péret, L. Laplaze, C. Franche, SymRK defines a common genetic basis for plant root endosymbioses with arbuscular mycorrhiza fungi, rhizobia, and Frankiabacteria. Proc. Natl. Acad. Sci. 105, 4928-4932 (2008).

40. S. Kosuta, M. Held, M. Hossain, G. Morieri, A. MacGillivary, C. Johansen, M. Antolín-Llovera, M. Parniske, G. Oldroyd, A. Downie, Lotus japonicus symRK-14 uncouples the cortical and epidermal symbiotic program. Plant J. 67, 929-940 (2011).

41. Y. Shimoda, L. Han, T. Yamazaki, R. Suzuki, M. Hayashi, H. Imaizumi-Anraku, Rhizobial and fungal symbioses show different requirements for calmodulin binding to calcium calmodulin-dependent protein kinase in Lotus japonicus. Plant Cell 24, 304-321 (2012).

42. N. Takeda, T. Maekawa, M. Hayashi, Nuclear-localized and deregulated calcium-and calmodulin-dependent protein kinase activates rhizobial and mycorrhizal responses in Lotus japonicus. Plant Cell 24, 810-822 (2012).

43. G. Estrada-Navarrete, X. Alvarado-Affantranger, J.-E. Olivares, G. Guillén, C. Díaz-Camino, F. Campos, C. Quinto, P. M. Gresshoff, F. Sanchez, Fast, efficient and reproducible genetic transformation of Phaseolus spp. by Agrobacterium rhizogenes. Nat. Protoc. 2, 1819 (2007). 
44. M. K. Arthikala, R. Sánchez-López, N. Nava, O. Santana, L. Cárdenas, C. Quinto, RbohB, a Phaseolus vulgaris NADPH oxidase gene, enhances symbiosome number, bacteroid size, and nitrogen fixation in nodules and impairs mycorrhizal colonization. New Phytol. 202, 886-900 (2014).

45. N. Molinero-Rosales, J. Á. Martín-Rodríguez, T. Ho-Plágaro, J. M. García-Garrido, Identification and expression analysis of the arbuscular mycorrhiza-inducible Rieske non-heme oxygenase Ptc52 gene from tomato. J. Plant Physiol., (2019).

46. A. Martinez-Medina, L. Pescador, I. Fernandez, M. Rodríguez-Serrano, J. M. García, M. C. Romero-Puertas, M. J. Pozo, Nitric oxide and phytoglobin PHYTOGB 1 are regulatory elements in the Solanum lycopersicum-Rhizophagus irregularis mycorrhizal symbiosis. New Phytol., (2019).

47. K. Akiyama, K. Matsuzaki, H. Hayashi, Plant sesquiterpenes induce hyphal branching in arbuscular mycorrhizal fungi. Nature 435, 824-827 (2005).

48. G. Nagahashi, D. D. Douds, Partial separation of root exudate components and their effects upon the growth of germinated spores of AM fungi. Mycol. Res. 104, 1453-1464 (2000).

49. E. Limpens, J. Ramos, C. Franken, V. Raz, B. Compaan, H. Franssen, T. Bisseling, R. Geurts, RNA interference in Agrobacterium rhizogenes-transformed roots of Arabidopsis and Medicago truncatula. J. Exp. Bot. 55, 983-992 (2004).

50. S. Sinharoy, C. I. Pislariu, M. K. Udvardi, A High-Throughput RNA Interference (RNAi)-Based Approach Using Hairy Roots for the Study of Plant-Rhizobia Interactions. Plant Gene Silencing: Methods and Protocols, 159-178 (2015).

51. R. Jefferson, The GUS reporter gene system. Nature 342, 837 (1989).

52. R. Nagy, V. Karandashov, V. Chague, K. Kalinkevich, M. B. Tamasloukht, G. Xu, I. Jakobsen, A. A. Levy, N. Amrhein, M. Bucher, The characterization of novel mycorrhiza-specific phosphate transporters from Lycopersicon esculentum and Solanum tuberosum uncovers functional redundancy in symbiotic phosphate transport in solanaceous species. Plant J. 42, 236-250 (2005).

53. J. M. Phillips, D. Hayman, Improved procedures for clearing roots and staining parasitic and vesicular-arbuscular mycorrhizal fungi for rapid assessment of infection. Trans. Br. Mycol. Soc. 55, 158IN116-161IN118 (1970).

54. M. Giovannetti, B. Mosse, An evaluation of techniques for measuring vesicular arbuscular mycorrhizal infection in roots. New Phytol. 84, 489-500 (1980).

55. A. Trouvelot, Mesure du taux de mycorhization VA d'un systeme radiculaire. Recherche de methodes d'estimation ayant une significantion fonctionnelle. Mycorrhizae: physiology and genetics, 217221 (1986).

56. W. Peters, I. Latka, Electron microscopic localization of chitin using colloidal gold labelled with wheat germ agglutinin. Histochem. Cell Biol. 84, 155-160 (1986).

57. P. Pimprikar, S. Carbonnel, M. Paries, K. Katzer, V. Klingl, M. J. Bohmer, L. Karl, D. S. Floss, M. J. Harrison, M. Parniske, A CCaMK-CYCLOPS-DELLA complex activates transcription of RAM1 to regulate arbuscule branching. Curr. Biol. 26, 987-998 (2016).

58. E. Gobbato, J. F. Marsh, T. Vernié, E. Wang, F. Maillet, J. Kim, J. B. Miller, J. Sun, S. A. Bano, P. Ratet, A GRAS-type transcription factor with a specific function in mycorrhizal signaling. Curr. Biol. 22, 2236-2241 (2012).

59. X. Zhang, N. Pumplin, S. Ivanov, M. J. Harrison, EXO70I Is Required for Development of a Sub-domain of the Periarbuscular Membrane during Arbuscular Mycorrhizal Symbiosis. Curr. Biol. 25, 2189-2195 (2015). 
60. A. Genre, S. Ivanov, M. Fendrych, A. Faccio, V. Žárský, T. Bisseling, P. Bonfante, Multiple exocytotic markers accumulate at the sites of perifungal membrane biogenesis in arbuscular mycorrhizas. Plant Cell Physiol. 53, 244-255 (2011).

61. N. Feddermann, D. Reinhardt, Conserved residues in the ankyrin domain of VAPYRIN indicate potential protein-protein interaction surfaces. Plant Signal Behav 6, 680-684 (2011).

62. E. Wang, S. Schornack, J. F. Marsh, E. Gobbato, B. Schwessinger, P. Eastmond, M. Schultze, S. Kamoun, G. E. Oldroyd, A common signaling process that promotes mycorrhizal and oomycete colonization of plants. Curr. Biol. 22, 2242-2246 (2012).

63. Y. Kobae, S. Hata, Dynamics of periarbuscular membranes visualized with a fluorescent phosphate transporter in arbuscular mycorrhizal roots of rice. Plant Cell Physiol. 51, 341-353 (2010).

64. H. Kumagai, H. Kouchi, Gene silencing by expression of hairpin RNA in Lotus japonicus roots and root nodules. Mol. Plant-Microbe Interact. 16, 663-668 (2003).

65. C. Mrosk, S. Forner, G. Hause, H. Kuster, J. Kopka, B. Hause, Composite Medicago truncatula plants harbouring Agrobacterium rhizogenes-transformed roots reveal normal mycorrhization by Glomus intraradices. J. Exp. Bot. 60, 3797-3807 (2009).

66. T. Schmülling, J. Schell, A. Spena, Single genes from Agrobacterium rhizogenes influence plant development. The EMBO journal 7, 2621-2629 (1988).

67. V. P. Bulgakov, Functions of rol genes in plant secondary metabolism. Biotechnol. Adv. 26, 318324 (2008).

68. M.-C. Auriac, A. C. Timmers, Nodulation studies in the model legume Medicago truncatula: Advantages of using the constitutive EF1 $\alpha$ promoter and limitations in detecting fluorescent reporter proteins in nodule tissues. Mol. Plant-Microbe Interact. 20, 1040-1047 (2007). 